\title{
TENDENCIAS MODERNAS DE DISEÑO ORGANIZACIONAL: redes organizacionales internacionales en zonas regionales
}

\author{
1- Jose Enrique Louffat Olivares \\ Escuela de Administración de Negocios para Graduados - ESAN \\ elouffat@esan.edu.pe
}

Diego Maganhotto Coraiola - Editor

\section{RESUMEN}

El presente documento busca analizar y correlacionar cualitativamente como el más reciente modelo de diseño organizacional, a saber "la estructura organizacional en red" se convierte en una opción estratégica, estructural y operacional ideal para las actividades de internacionalización de empresas (negocios internacionales) con foco en la zona regional latinoamericana. Para tal efecto se emplearan dos categorías de análisis: la primera denominada de condicionantes organizacionales y cuyas variables serán, la estrategia, el ambiente, la tecnología y la cultura organizacional; la segunda denominada de componentes organizacionales contempla las variables departamentalización, actividades de línea y de staff, la descripción de actividades, la cadena jerárquica, centralización/descentralización y la comunicación. A modo de ilustración de los conceptos teóricos planteados se presentan tres casos de corporaciones empresariales - una de origen peruana, otra de origen alemana y otra de origen mexicana- con actividades en la región latinoamericana, donde se aprecian aplicaciones particulares del modelo de configuración corporativa del modelo de red.

Palabras-Claves

Diseño organizacional, Redes organizacionales, negocios internacionales.

\section{ABSTRACT}

The present document seeks to analyze and link qualitatively how the most recent organizational design model, that is "the organizational structure in network", becomes the strategic option, the structural and operational archetype for all activities for entrepreneurial internationalization (international businesses), focused in the Latin American region. To that effect, there are two categories of analysis used: the first is called organizational conditioners whose variables would be strategy, environment, technology and organizational culture; the second, called organizational components, looks into departmentalization variables, activities of line and staff, the activities description, hierarchy chain, centralization/decentralization and communication. To illustrate the theoretic concepts established there are three cases of entrepreneurial corporations - one is of Peruvian origin, the second is German, and the third is Mexican - with activities in the Latin American region, where the peculiar application of the corporative configuration of the network model can be noticed.

Keywords

Organizational design, organizational networks, international business. 


\section{Contextualización}

La internacionalización de negocios, entendida como la acción administrativa por la cual empresas locales-nacionales deciden ampliar su ámbito de acción para zonas internacionales, se ha convertido en una alternativa cada vez más adoptada en el moderno contexto de los negocios. Si bien es cierto los negocios internacionales siempre han existido en las diversas épocas históricas de la humanidad, en la última década del siglo pasado surgió el fenómeno de la globalización (IANNI, 1997) el cual le dio un nuevo impulso para poder convertirse hoy en día en una opción consistente, factible y rentable, la que se ha venido fortaleciendo con la firma de tratados y acuerdos comerciales internacionales (NAFTA, MERCOSUR, Comunidad Europea, etc.).Esta apertura comercial de los países ha sido la clave para impulsar y vigorizar los negocios internacionales. En ese contexto las empresas de diversos países se han visto en la necesidad de afrontar nuevos retos y desafíos, entre ellos el de la "competitividad", es decir, ser eficaz y eficiente para poder enfrentar la competencia de calidad internacional. Este reto de internacionalización no sólo se refiere a corporaciones de prestigio y talla mundial sino también a medianas y pequeñas empresas que eventualmente podrían formar parte de alianzas y/o redes estratégicas. No cabe duda que esta situación ha influenciado para que las empresas adopten nuevas posturas estratégicas, estructurales y operacionales que les permita ser competitivas en el ámbito internacional. En ese contexto el diseño organizacional es uno de los aspectos que se ha convertido en un factor de ventaja competitiva. Hasta los años noventas, los modelos organizacionales imperantes y caracterizados por ser rígidos, ineptos, inflados, lentos eran los consabidos: funcional, geográfico, por clientes, por productos, por cantidad, por turnos, por divisiones o áreas estratégicas de negocios, por proyectos, matricial. Sin embargo ellos no estaban respondiendo completamente a los nuevos retos y desafíos de flexibilidad, renovación, rapidez y competitividad. Por eso es que surge la necesidad de descubrir alguna otra forma de rediseñar las organizaciones que hiciera factible el funcionamiento de las mismas. Es así que nace la propuesta de una estructura organizacional en red, la cual traería consigo elementos y características que innovaban y complementaban a las ya existentes. El modelo en red ha venido a revolucionar la administración de empresas, entre sus principales características cabe destacar, la visión de procesos, la poli funcionalidad de los trabajadores, las células de trabajo, su flexibilidad y capacidad de adaptación contingencial, conjunción de expertises y knowhow técnico, reducción de niveles jerárquicos, entre otras. El modelo en red puede aplicarse tanto a nivel interno (dentro de una empresa/corporación) o a nivel externo (entre varias empresas/ corporaciones), mediante alianzas estratégicas, en diversos sectores económicos y diferentes ámbitos de acción. Justamente ha sido la internacionalización de los negocios en donde este modelo ha encontrado una gran acogida, por la cual empresas buscan integrar sinérgicamente sus sedes-matrices y sus diversas subsidiarias en otros países, procurando modelos de diseño organizacional sinérgicos, compactos, flexibles y rentables, actuando a nivel global, multinacional, internacional y/o transnacional.

En ese contexto el propósito de este ensayo es el de analizar las características de la correlación cualitativa entre el diseño organizacional en red como contexto de actuación de empresas con actividades de internacionalización con foco en la zona regional latinoamericana.

\subsection{Objetivo}

Analizar como el diseño de una estructura organizacional en red opera en contexto de redes organizacionales internacionales con énfasis en la zona regional latinoamericana.

\subsection{Premisa (a modo de Hipótesis)}

El diseño de una estructura organizacional en red es una alternativa para ser implementada en un contexto de redes organizacionales internacionales con foco en la zona regional latinoamericana.

\subsection{Marco teórico}

A efectos de desarrollar el análisis de la estructura organizacional en red en empresas internacionalizadas, optamos por aplicar el siguiente modelo básico de investigación, el cual está constituido por dos dimensiones: condicionantes y componentes. De un lado condicionantes son los elementos de origen exógeno, a nivel macro-organizacional, constituidos por las siguientes variables: estrategia, ambiente, tecnología y cultura; de otro 
lado, componentes son los elementos de origen endógeno a nivel micro-organizacional, constituidos por las siguientes variables: departamentalización (D), actividades de línea/staff (L/S), descripción de actividades (DA), cadena jerárquica (CJ), nivel de centralización/descentralización (C/D), comunicación (C). Es bueno resaltar que estas variables son aspectos consolidados en la teoría del diseño organizacional y nos sirven de soporte para conocer su aplicación en empresas internacionalizadas (VASCONCELLOS, 1972; GALBRAITH, 1977; OSBORNT; HUNT; JAUCH, 1980; ROBBINS, 1986; HALL, 1984; GIBSON; IVACENEVICH; DONNELY, 1988; PRAHALAD; HAMEL, 1990; BEDEIAN \& ZAMMUTO, 1991; JONES,1995; OLIVEIRA, 1995; BATEMAN.; SNELL, 1998).Asimismo se considera dentro del modelo, la taxonomia de internacionalización de negocios, propuesta por BARLETT \& GOSHAL (1992) y que contempla cuatro posibilidades de modelos internacionales en la relación matrizsubsidiarias: Modelo global, Modelo multinacional, Modelo internacional, Modelo transnacional.

\section{Estructura Organizacional en Red}

\section{Concepto}

La estructura organizacional en red conocida también como organización red, organización sin fronteras, network, organización cosmos, organización constelación, organización celular, etc., puede ser definida como:"la red o armazón que sirve de base para el funcionamiento simultáneo, coordinado, equilibrado e integrado entre las unidades orgánicas de una o mas organizaciones, pues presenta las diversas relaciones intra $y / 0$ interorganizacionales existentes entre los diferentes elementos que la conforman. Estas interrelaciones comprenden aspectos técnicos y comportamentales, basados en los condicionantes y componentes que influencia su propio diseño" (LOUFFAT, 2003, p. 21). Como se puede notar el término red puede tener un contexto interno, dentro de una única organización y/o empresas de una misma corporación ("de un mismo dueño"); o un contexto externo de interdependencia de dos o más organizaciones y/o empresas de diversas corporaciones ("de dos o más dueños diferentes) bajo alguna forma de alianza estratégica. Independientemente de esas alternativas - interna o externa-, los principios y características básicas de red son las mismas. Para efectos del presente trabajo focalizaremos esencialmente una red de tipo interna, donde una corporación con sede matriz en un país establece su red interna con sedes subsidiarias de su propiedad en otros países. Eventualmente podría considerarse relaciones externas de la sede matriz y/o de sus subsidiarias (alianzas estratégicas con otras corporaciones/empresas).

\section{Elementos}

Toda estructura organizacional red (EOR) basa su configuración y modus operandi en dos elementos: el primero de ellos son las células conocidas también como nudos, polos, estaciones o equipos y se refieren a la constitución de unidades orgánicas formales y/o informales; el segundo elemento son las líneas que funcionan como conectores, enlaces entre las células. El funcionamiento relacionado y sinérgico de la red se da por la combinación e intercambio de procesos y conexiones burocráticas (ordenes, estándares compartidos, procedimientos) económicas (transacciones materiales, monetarias), operativas (trabajo en común, toma de decisiones colectivas, recursos compartidos), culturales (valores compartidos, comunidad de situación) e informativas (acceso, intercambio compartido de informaciones).

\section{Taxonomia}

Las tipologías de redes son variadas, siendo necesario siempre definirlas para poderlas contextualizar específicamente, de acuerdo al análisis a ser realizado. Sólo a título de ilustración presentamos algunas de ellas, debiendo aclarar que para efectos clasificatorios se podrían conjugar simultáneamente las opciones propuestas (LOUFFAT, 2003, p. 22-27): a) De acuerdo a la nacionalidad, la EOR puede ser local (células del mismo país), o Internacional (células de países diferentes); b) De acuerdo al número, la EOR puede ser Bi-Red (dos células) o Poli-Red (más de dos células); c) De acuerdo a la propiedad, la EOR puede ser Privada (células de dueños privados) o Pública (células de dueños del sector público); d) De acuerdo al desarrollo de procesos conjuntos, la EOR puede ser Integrada (células aplican varios procesos de negocios simultáneos. Ejemplo Marketing, Finanzas, Operaciones, RRHH, etc.) o Específica (células aplican solo un proceso de negocio. Ejemplo: marketing); e) De acuerdo al sentido abstractoconcreto, la EOR puede ser Física (células se relacionan de modo concreto, visible, tangible por medios mecánicos-físicos) o Virtual (células se 
relacionan de forma abstracta, intangible por medios electrónicos); f) De acuerdo al ámbito de la relación, la EOR puede ser Interna (relación entre células de un mismo dueño) o Externa (relación entre células de diferentes dueños); g) De acuerdo al status de la relación, la EOR puede ser formal (células basan sus acuerdos legales registrados) o Informal (células basan sus acuerdos en "palabra", sin documentos de por medio); h) De acuerdo al tiempo de duración, la EOR puede ser Permanente (cuando las células estipulan un periodo determinado) o Variable (cuando las células tiene libertad para afiliarse o desafiliarse libremente, previo aviso anticipatorio); i) De acuerdo al sector de actuación, la EOR puede ser Industrial (células del ramo de industrias), Comercial (células de actividades de comercio) o de Servicios (células de actividades de servicios. Ejemplo. Red de hospitales, escuelas); j) De acuerdo al porte de la empresa, la EOR puede ser Similar (células de tamaño similar) o No similares (células de tamaños diferente).

Figura 1 - Modelo de análisis

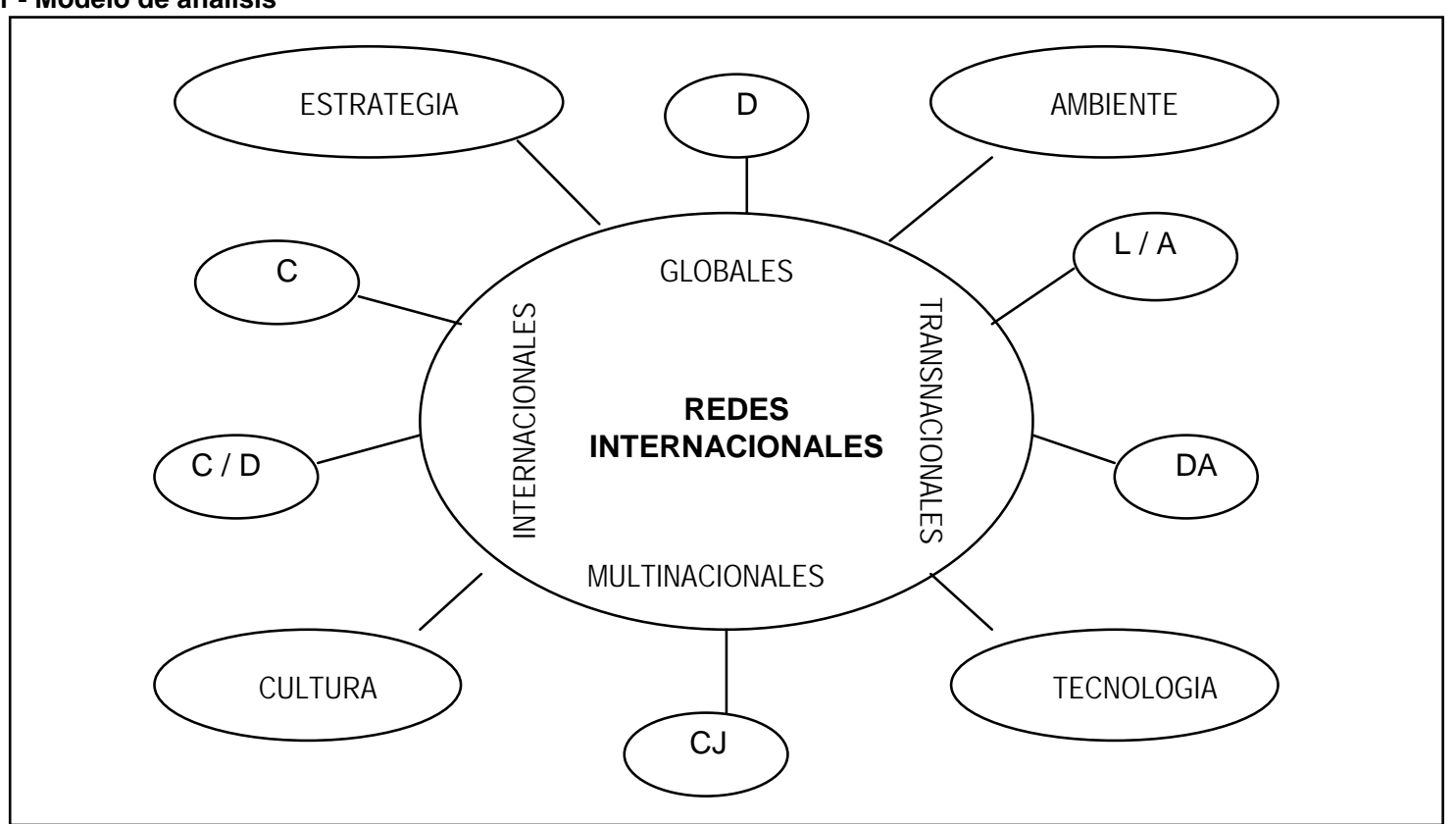

Fuente: Elaboración propia

\section{Condicionantes}

Son variables de nivel macroorganizacional que influencian en el diseño y dinámica de la estructura organizacional en red. En el presente trabajo se consignan las siguientes condicionantes:

- Estrategia, se refiere a la postura de la corporación red en cuanto al modelo de internacionalización a ser adoptado.

- Ambiente, se refiere al contexto e influencias que la corporación red recibe del macroambiente organizacional (economía, políticas, sociales, etc.) así como del microambiente organizacional (stakeholders).
- Tecnología, se refiere al empleo de tecnologías informáticas virtuales como soporte al funcionamiento de las redes.

- Cultura organizacional, se refiere al contexto de valores y principios como elementos de integración organizacional.

\section{Componentes}

Son variables de nivel microorganizacional que determina el perfil del diseño adoptado por la estructura organizacional en red. En el presente trabajo se consignan los siguientes componentes:

- Departa mentalización (D), se refiere a la estructura seleccionada para el funcionamiento de la red. 
- Línea / Asesoria (L/A), se refiere a la relación entre las unidades de línea y las unidades de asesoría dentro de la red.

- Descripción de actividades (DA), se refiere al grado de cantidad y calidad de la normatividad organizacional definida $y$ empleada en la red (manuales, reglamentos, etc.)

- Cadena jerárquica (CJ), se refiere a la cantidad de niveles jerárquicos establecidos en la red.

- Centralización / Descentralización (C/D), se refiere al grado de delegación de autoridad y responsabilidad a las diversas unidades orgánicas de la red.

- Comunicación (C), se refiere al estilo, mecanismo y procesos de comunicación entre el personal de la red.

\section{Negocios internacionales}

\section{Término y concepto}

Un primer punto de referencia sería determinar la nomenclatura de la empresa con actividades de internacionalización. ¿Será acaso, una empresa mundial, internacional, global, multinacional, transnacional? En la literatura no existe un consenso sobre el empleo de una $u$ otra denominación. En el presente documento para efectos de uniformización se empleará como término de referencia "empresas internacionalizadas", la cual puede ser definida como "aquella empresa que tiene actividades estratégicas, estructurales y/u operacionales en más de un País". Entiéndase que las actividades empresariales se fundamentan en el empleo de recursos físicos, materiales, financieros $\mathrm{y} / \mathrm{o}$ humanos, en aspectos mercadológicos, de producción, de finanzas, de logística, etc.

\section{$\underline{\text { Tipos }}$}

La empresa que desee desarrollar actividades empresariales de internacionalización en otros países (GROSSE; KUJAWA, 1992) tienen algunas opciones básicas para hacerlo (MONTANA; CHARNOV, 2003, p. 448): a) Internacionalización Indirecta, constituida por operaciones de exportación y/o comercialización de productos, servicios, marcas/patentes, donde la empresa matriz, no desarrolla actividades "físicas" sino por medio de otras empresas intermediarias. Entre ellas tenemos: exportación directa, licenciamiento, franchising; b) Internacionalización Directa (subsidiarias) constituidas por operaciones integrales 0 parciales de la matriz en países extranjeros. Entre ellas tenemos: Inversiones directas, joint ventures, proyectos de negocios, contratos de gestión

\section{Modelos}

Dentro de las propuestas sobre conceptuaciones y definiciones teóricas analizadas, la propuesta establecida por BARTLETT \& GHOSHAL (1992) es una de las referencias centrales en el tema de internacionalización de empresas, ellos hacen una exposición sobre cuatro modelos generales de internacionalización de empresas, las cuales determinan la relación entre la sede-matriz de la corporación situada en un país con sus subsidiarias sediadas en otros países, en relación a sus procesos de administración de negocios (planear, organizar, dirigir y controlar) en sus diversas áreas de expertise (Marketing, Finanzas, Logística, RRHH, etc.), gestión de recursos (materiales, financieros y humanos) a saber:

a) Multinacional, es aquel modelo por el cual la sede-matriz otorga autonomía a las subsidiarias para que puedan adaptar a sus contextos de actuación, las directrices corporativas centrales. Por ejemplo establece que todos los comerciales que se pasen en las diversas sedes de sus subsidiarias deberán ser creaciones particulares para cada contexto o realidad.

b) Global, es aquel modelo por el cual la sedematriz no otorga autonomía a las subsidiarias para que puedan adaptar a sus contextos de actuación, las directrices corporativas centrales. Por ejemplo establece que los procesos de gestión de personas deberán ceñirse a las directivas emanadas de la matriz

c) Internacional, es aquel modelo por el cual, en el caso que alguna directriz corporativa central sea superada o mejorada por alguna de las subsidiarias en su contexto, cabria la posibilidad que la sede matriz se la solicite a dicha subsidiaria para, previo análisis estratégico centralizado, poder implantarla en ella y eventualmente en las demás subsidiarias. Por ejemplo si una de las subsidiarias pudiese mejorase los estándares y/o productividad algún proceso de producción o servicio en relación a las 
otras sedes, es potestad de la sede matriz que pueda incorporarlo a las demás sedes de las otras subsidiarias.

d) Transnacional, es aquel modelo por el cual, en el caso que alguna directriz corporativa central sea superada o mejorada por alguna de las subsidiarias, ésta y el resto de subsidiarias están autorizada a intercambiar propuestas directamente "sin pasar previamente" por la matriz central. Es decir habría un trato directo entre subsidiarias donde el papel de las subsidiarias es de contribuciones diferenciadas a favor de operaciones mundiales integradas, siendo que el know how es desarrollado en conjunto $y$ compartido en toda la red mundial. Por ejemplo si una de las subsidiarias pudiese mejorase los estándares y/o productividad algún proceso de producción o servicio en relación a las otras sedes, es potestad de que pueda transferir directamente ese know how a las otras sedes, sin necesariamente remitirlo primeramente a la sede matriz. El modelo transnacional es aquel que desarrolla simultáneamente la competitividad global, la flexibilidad multinacional y la capacidad de aprendizaje mundial.

En complemento a los modelos señalados anteriormente, el aspecto cultural podría regirse basado en fundamentos de a) etnocentrismo, es decir la aplicación de una cultura corporativa emanada e impuesta por la sede matriz según sus valores y concepciones basadas en el País de origen; b) policentrismo, cuando la sede matriz no impone una cultura sino permite que hayan aplicaciones culturales locales según las influencias locales en sedes de los países donde sus ubican sus sedes subsidiarais y c) geocentrismo, seria una combinación hibrida de las propuestas anteriores.

\section{Metodología}

La investigación desarrollada es de tipo cualitativo a nivel exploratorio. (CRESWELL, 1994, p. 5; GIL, 1988, p. 45-48; SELLTIZ, 1964, p. 60; YIN, 1989, p. 23; PATTON, 1990, p. 4041).Para la colecta de datos en esta investigación fueron empleadas: fuentes primarias, a través de 12 entrevistas semi-estructuradas con ejecutivos de cada una de las corporaciones presentadas en este estudio con una duración aproximada de 45 minutos, 6 fueron realizadas presencialmente y las otras 6 por medios virtuales; fuentes secundarias, a través de la consulta de documentos internos de las empresas y publicaciones externas.El tratamiento de la información fue realizada por medio de la técnica de análisis de contenido (BARDIN, 1977). Esta técnica permite que a través de una descripción objetiva sistemática y cualitativa del contenido manifiesto de las comunicaciones se centre la interpretación de estas comunicaciones, siendo sus etapas principales las siguientes:

Etapa 1: Selección de documentos, sean entrevistas transcritas, sean documentos internos o publicaciones externas; etapa 2: Formulación de objetivos/cuestiones, buscando "nortear" el sentido de la investigación, a saber la estructura organizacional de la internacionalización empresarial; etapa 3: Categorización: a través del modelo de investigación propuesto con los diversos condicionantes y componentes y sus respectivos componentes; etapa 4: Codificación/unidades de análisis: agrupando las respuestas e informaciones encontradas en las categorías establecidas anteriormente; etapa 5: inferencia/resultados: a través de un modelo combinado para poder sustentar la validad y confiabilidad de los resultados encontrados.

\section{Casos}

A efectos de analizar el modelo planteado, así como mostrar características reales sobre el mismo, procedemos a presentar tres casos ilustrativos de corporaciones con actividades en el Perú y Latinoamérica, una de propietarios nacionales y las otras de propietarios extranjeros. La elección de los casos de estudios se basó en los siguientes criterios:

- Con actividades de internacionalización en Latinoamérica, por ser el ámbito de estudio.

- Ser líderes en sus respectivos mercados, y ser tomados como ejemplos de benchmarking

- Mínimo 10 años aplicando características de redes. Tiempo mínimo necesario para poder comprobar su sostenibilidad, por lo menos a mediano plazo

- Pertenecer a sectores diferentes para poder observar sus diversos matices de aplicación de una red. 
Es bueno señalar que se nos ha pedido mantenerlas en el anonimato, motivo por el cual no podemos presentarlas con sus nombres/marcas oficiales ni tampoco citar o profundizar informaciones cuantitativas estratégicas y en todo caso eventualmente se presentaran informaciones ficticias modificadas en relación a los datos verídicos. Este hecho no perjudica en nada el desarrollo de esta investigación ya que se focaliza en el tema de diseño organizacional.

\subsection{Caso 1: Corporación BELLEZA}

Es una corporación peruana fundada en 1985, con presencia en 12 países (Argentina, Bolivia, Chile, Colombia, Costa Rica, Ecuador, El Salvador, Francia, Guatemala, México, Puerto Rico, República Dominicana, Venezuela y USA) dedicada a la producción y comercialización de productos cosméticos (maquillaje, cremas, etc.) bijuteria, perfumería, y en menor escala, prendas de vestir. La corporación trabaja con tres líneas de marcas: BELA, DONA, GUAPA, las dos primeras dirigidas a clientes ejecutivas de clases altas A-B y la tercera dirigida a jóvenes de clases medias B-C. Se puede deducir que principalmente sus clientes principales son del sexo femenino, pero hay también productos dirigidos, en menor medida, a varones. Se estima que en su sector de actuación ocupa el segundo lugar, sólo siendo superada por otra corporación transnacional.

La estructura red adopta la siguiente configuración: corporación BELLEZA tiene centralizada en Lima, algunas funciones administrativas como son Finanzas, $\mathrm{RRHH}$, Informática, Abastecimiento, Investigación \& Desarrollo. Las labores de elaboración (Producción) son tercerizadas en Corporación PRODUCTOR (de dueños diferentes), quienes fabrican a solicitud o encomienda de Corporación BELLEZA, asimismo desarrolla actividades de operador logístico distribuyendo internacionalmente los stocks a todas las subsidiarias de Corporación BELLEZA, subsidiarias que principalmente desarrollan actividades de comercialización. Es bueno también señalar que existen algunas otra empresas creadas dentro de la corporación para cumplir algunas funciones especificas: la empresa COBREMOS encargada de las cobranzas dentro del Perú; la empresa PROMOCA, encargada de las labores de promoción de ventas en Perú.
También la red cuenta con dos empresas de propiedad de la corporación pero cuyo radio de acción no se limita al Perú sino que actúa en las subsidiarias internacionales: la empresa INVESTIMERCA, encargada de asesorar en las labores de investigación de mercados y la empresa GLOBUS, encargada de dar asesoría en el área comercial. La corporación BELLEZA representa su organigrama corporativo de la siguiente forma (figura 3).

\section{Análisis del caso 1}

La Internacionalización de la corporación BELLEZA puede ser considerada como de tipo directa, ya que procura desarrollar actividades con sede propia en los países donde tiene operaciones con énfasis en procesos de negocios de comercialización. En cuanto al modelo de internacionalización la corporación presenta rasgos característicos de empresas globales, por la cual la sede-matriz otorga poca autonomía a sus sedes subsidiarias, buscando más bien estandarizar los procesos de negocios internacionales. La configuración red adoptada por esta corporación puedes ser detallada como: De acuerdo a la nacionalidad, es de un solo país, ya que los propietarios son de nacionalidad peruana; De acuerdo al número, dentro del mismo grupo tiene cinco empresas participantes y una empresa externa contratada (tercerizada); De acuerdo a la propiedad, es de capital privado; De acuerdo al desarrollo de procesos, se plantean varios procesos de negocios integrados centralizados y estandarizados (Marketing, Operaciones, T.I, etc.); De acuerdo al sentido abstracto-concreto, hay un mix de lo virtual por medio de la aplicación de software integrados de gestión) y la parte física. Por medio de las operaciones logísticas internacionales y nacionales; De acuerdo al ámbito de la relación, esta es interna porque se desarrolla dentro de la corporación y sus propias empresas y con el matiz de una empresa externa pero tercerizada; De acuerdo al status de la relación, esta es formal; De acuerdo al tiempo de duración, tiene una proyección indefinida a futuro; De acuerdo al sector de actuación, actúa en un mix básico de actuación en el sector comercial. Ésta se desarrolla en el ámbito comercial; De acuerdo al porte de la empresa, es no similar, ya que las operaciones en diversos países tienen diversos niveles y proporciones. 
Figura 2 - Red de corporación BELLEZA

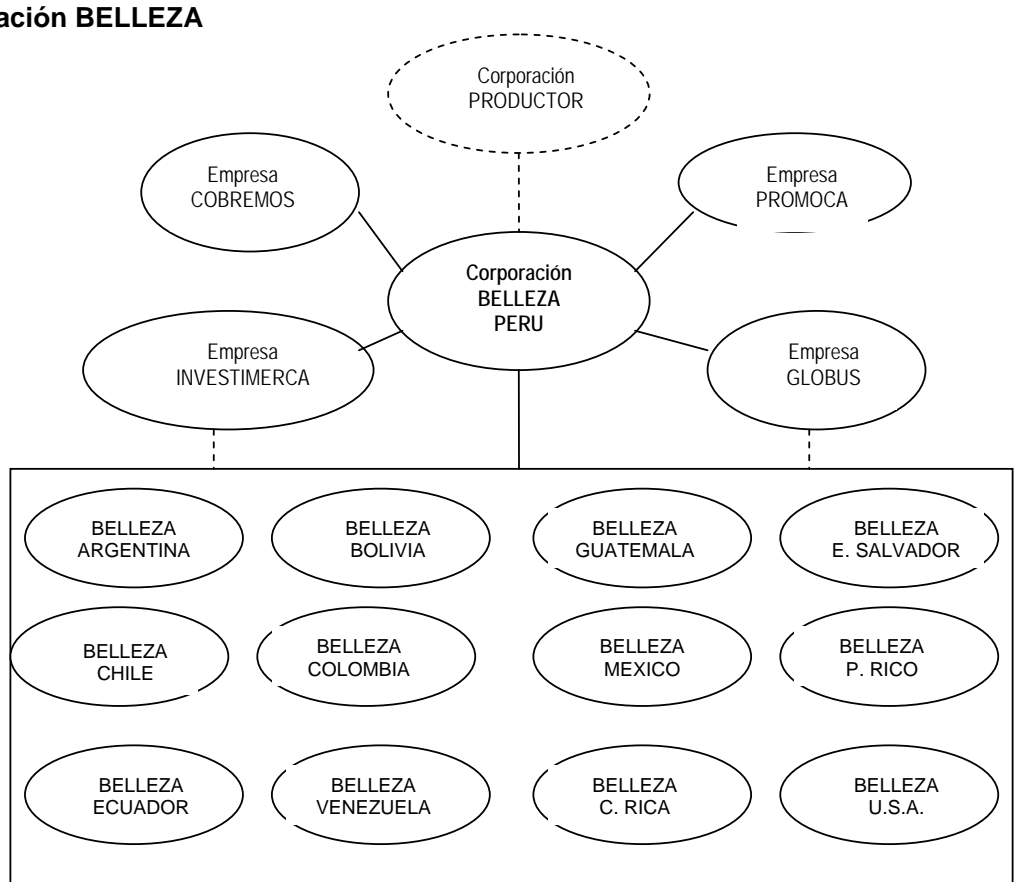

Fuente: Elaboración propia

Figura 3 -Estructura Organizacional de Corporación BELLEZA

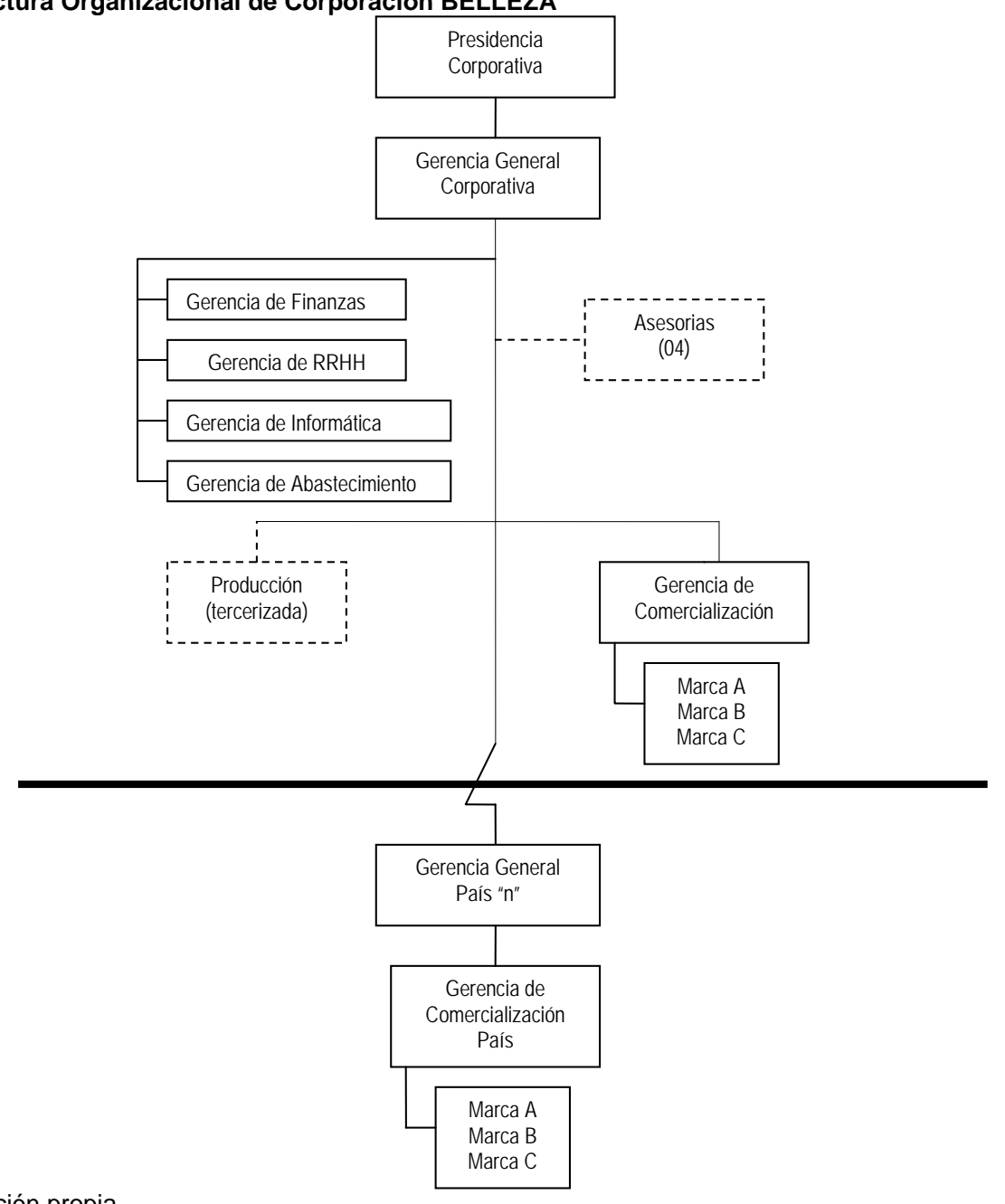

Fuente: Elaboración propia 


\section{Condicionantes}

- Estrategia, la corporación busca conciliar el "trípode estratégico": liderazgo en costos, empleando la estandarización de procesos de negocios por medio de la configuración de red con empresas del grupo - COBREMOS, PROMOCA, INVESTMERCA, GLOBAL - y con una empresa tercerizada PRODUCTOR; asimismo focaliza sus actividades en el mercado de productos de belleza, bijouterie y conexos para principalmente en el segmento mujeres de padrón de renta medio-alto, alto; y trata permanentemente de diferenciarse de la competencia en base a sus actividades de investigación \& desarrollo y de investigación \& mercados.

- Ambiente, económicamente el Perú es un país con una economía estable en los últimos años, políticamente también hay cierta normalidad institucional basada en principios democráticos. El hecho que los integrantes de la red de la corporación sobretodo en su sede matriz sean peruanos, hacen que todos actúen dentro del mismo contexto. Siendo ésta su base, la internacionalización de los negocios principalmente a otros países sudamericanos y por complemento a países centroamericanos, implica poder buscar mercados donde las costumbres, estilos de vida y características no guardan muchas diferencias en los gustos y productos a ofrecer. En cuanto a su micro ambiente de negocios, el accionariado esta constituido por capitales peruanos en un 100\%; la principal forma de ventas es por una red de consultoras de belleza principalmente, ya en las sedes internacionales la venta es por medio de tiendas en malls o lugares referentes de belleza; en cuanto a los proveedores, estos son diversos a nivel internacional, dependiendo del insumo a adquirir; en cuanto a los competencia, dentro del Perú tienen un market share de 30\% aproximadamente, siendo la primera empresa peruana en el sector.

- Tecnología, esta aspecto es uno de lo puntos fuertes del funcionamiento de la red, en cuanto a tener desarrollado sistemas informáticos modulares que integran sus diversos procesos de gestión (operaciones, finanzas, marketing, RRHH, etc.). Por lo general estos programas o software son mandados diseñados "a su medida" a empresas consultoras internacionales en informática.
- Cultura, la postura cultural de la corporación BELLEZA es de tipo hibrida, es decir una combinación de etnocentrismo, donde se pretende determinar tanto en las empresas de la red - COBREMOS, PROMOCA, INVESTMERCA, GLOBAL- como en las subsidiarias internacionales ciertos padrones de comportamiento, según las indicaciones de la sede matriz. Pero por otro lado se otorga cierto grado de policentrismo para que cada subsidiaria internacional pueda adoptar o establecer patrones de comportamiento según su propio contexto nacional.

\section{Componentes}

- Departamentalización, la organimetría determina una configuración de red a nivel corporativo, ya que se presenta el funcionamiento coordinado, sinérgico e integrado de una sede matriz con empresas de la misma corporación, con una empresa tercerizada para procesos fabriles $y$ logísticos. Asimismo en la configuración misma de la sede matriz se observa un modelo funcional donde se privilegia las áreas de expertise pero con tendencia a integración por procesos de negocios, por medio de sus estandarizaciones en áreas de finanzas, RRH, TI y Abastecimiento. Su proceso core de línea es el de comercialización en sus tres líneas o marcas de productos y la cual se traslada a cada sede subsidiaria.

- Línea/Asesoria, en esta red la determinación de unidades asesoras y de línea están claramente definidas, así por ejemplo cuenta con 2 empresas asesoras que dan cobertura a toda la red INVESTMERCA, dedicada a aspectos de asesoria en investigación \& mercados y GLOBUS dedicada a actividades de asesoria en comercialización; 1 empresa asesora en Perú llamada PROMOCA, la cual desarrolla actividades de asesoria en promoción de ventas. De otro lado tiene una empresa ejecutora tercerizada, PRODUCTOR y otra de cobranzas coactivas denominada COBREMOS. También destacan las líneas ejecutoras de procesos de apoyo integrados de negocios (RRHH, Abastecimiento, TI y Finanzas) y lógicamente la unidad de línea ejecutora comercial en la sede matriz así como en las subsidiarias internacionales.

- Descripción de actividades, la corporación cuenta con manuales y documentos normativos acerca de los diversos procesos 
de negocios, ya que adopta una filosofía de estandarización internacional de negocios, donde todos los miembros de la red corporativa deben seguir los mismos padrones, y metodologías integradas para poder operacionalizar sus actividades en la búsqueda de rentabilidad y competitividad internacionalización.

- Cadena jerárquica, a nivel corporativo la corporación BELLEZA define claramente quien es el broker de la red, la sede matriz administra las relaciones con las otras empresas constituyentes de la red y sus subsidiarias internacionales. La sede matriz cuenta con 5 niveles jerárquicos integrando unidades de apoyo, de asesoria y/o de línea y cuyo poder nadie pone en duda.

- Centralización / descentralización, el modelo de red internacional global adoptado por la corporación BELLEZA se sustenta en la centralización de decisiones esenciales sobre sus procesos de negocios, de modo tal que el control y decisiones son tomadas en la matriz, las cuales deberán cumplirse tal y cual es emanada y se sustenta en sus sistemas integrados de gestión donde el seguimiento es permanente y en "vivo", con sistemas de control "just in time".

- Comunicación, ésta se desarrolla en forma virtual y presencial, la misma es de corte permanente, para poder coordinar e interconectar todas las actividades de la red.

\subsection{Caso 2: Corporación KAIZER}

Es una de las líderes mundiales del sector de industria química, fundada antes del siglo XX. .Su sede matriz es Alemania, y se encuentra presente en los cinco continentes, contando actualmente con aproximadamente 95,000 empleados en el mundo. Actúa en 5 segmentos de negocios:

- Químicos: especialidades inorgánicas, adhesivos, resinas, petroquímica, plastificantes, aminas, dioles, poli alcoholes, ácidos carboxílicos, especialidades intermedias.

- Plásticos: estireno, polímeros y copolimeros, nylon, plásticos de ingeniería, materiales básicos de poliuretano y sistemas de poliuretano, elastómeros especiales.

- Productos de performance (desempeño): materias primas para detergentes, químicos para cuero y textiles, pigmentos, aditivos para combustibles y lubricantes, pintura para automóviles, pinturas industriales, monómeros, súper absorbentes, materias primas para adhesivos, químicos para papel.

- Productos para agricultura y nutrición: herbicidas, fungicidas e insecticidas, vitaminas, ingredientes activos farmacéuticos, absorbentes de rayos UV.

- Petróleo y gas. Petróleo crudo y gas natural (exploración, producción y comercialización.

La configuración en red internacional de la corporación KAIZER esta constituida por la sedematriz en Alemania, cinco direcciones regionales mundiales y cada región están los países respectivos los cuales internamente dentro de su región también se agrupan como centro de negocios:

- Europa: Alemania, Austria, Belarusia, Bélgica, Bulgaria, Croacia, Republica Checa, Dinamarca, España, Finlandia, Francia, Gracia, Holanda, Hungria, Irlanda, Italia, Latvia, Lituania, Macedonia, Malta, Noruega, Polonia, Portugal, Reino Unido, Rumania, Rusia, Slovakia, Slovenia, Suecia, Suiza, Ucrania, Yugoslavia.

- América del Norte: América Central \& Caribe: Canada, Costa Rica, Republica Dominicana, El Salvador, Haiti, Honduras, Jamaica, México, Panamá, Puerto Rico, Trinidad Tobago, USA.

- África: Algeria, Egipto, Lybia, Marruecos, Sudáfrica, Tunes

- Asia/Asia-Pacifico: Australia, Bangladesh, China, India, Indonesia, Irán, Israel, Japon, Kazakistan, Malasia, Nepal, Nueva Zelandia, Pakistán, Filipinas, Katar, Singapur, Corea del Sur, Sri Lanka, Taiwán, Tailandia, Turquía, Emiratos Árabes Unidos, Uzbekistán, Vietnam.

- Sudamérica: Argentina, Bolivia, Brasil, Chile, Colombia, Cuba, Ecuador, Nicaragua, Paraguay, Perú, Uruguay, Venezuela.

En cada región forman centros de negocios constituidos por las sedes de los países de la región. A modo de referencia en la región sudamericana hay cuatro centros de negocios (figura 4): el del norte (Ecuador, Venezuela, Colombia); el del sur (Argentina, Bolivia, Uruguay y Paraguay); el del este (Brasil) y el del oeste (Perú y Chile).

La representación organimétrica jerárquica de la corporación KAIZER estaría representada 
como sigue: La primera vista (figura 5) muestra la alta Dirección de la corporación KAIZER con sede matriz en Alemania, constituida por el Consejo Directivo, la Presidencia Corporativa, las Direcciones Corporativas y los Direcciones Regionales. La segunda vista (figura 6) muestra como esta constituida una región, en ella figura un Director Regional, Directores Regionales y Gerentes de Centros de Negocios que agrupa a los países de la región. A modo ilustrativo se disgrega la Dirección Regional Sudamérica, con sede en Brasil, entendiéndose que en las otras regiones mundiales se estructura de la misma forma. El funcionamiento de la estructura se da por la relación estrecha y coordinada de expertise entre las Direcciones Corporativas de la matriz con las Direcciones Regionales y estas a su vez con las Direcciones de Centro de Negocios. Así, por ejemplo, una Dirección Corporativa de Finanzas imparte directrices a la Dirección Regional de Finanzas, quien a su vez coordina con la Gerencia de Finanzas de Centros de Negocios y que tienen como base la función finanzas en los países respectivos En general la idea de esta configuración es respetar los límites de actuación de las regiones bajo un principio de división zonal geográfico (centro de costos), es decir en principio todas las operaciones y procesos de negocios (Finanzas, Abastecimiento, $\mathrm{RRHH}$, etc.) Deben circunscribirse dentro de sus limites y con soporte en la integración de los centros de negocios, lo que significa que se van integrando, fusionando unidades orgánicas. Así, en vez de replicar en cada país una misma unidad orgánica, mejor se trabaja en función única y monolítica y se distribuye el expertise, reduciendo los costos innecesarios. En esta corporación hay algunas unidades orgánicas regionales de algún centro de negocios que dan cobertura parcial o a toda la región y/o a otros centros de negocios de la región, por ejemplo el pago a proveedores se realiza en sede de la Dirección Regional en Brasil; T.I es administrada desde el centro de negocios sur con apoyo de una empresa renombrada, etc.

\section{Análisis del caso 2}

La internacionalización de la corporación KAIZER puede ser considerada como de tipo directa, ya que desarrolla actividades in situ, con sede propia en las regiones y respectivos países pertenecientes a ellas. En cuanto al modelo de internacionalización adoptado puede ser considerado como un hibrido global, por las directrices estandarizadas a nivel mundial desde la matriz; multinacional, permitiéndose a las sedes regionales algunas adaptaciones locales e internacional, porque en casos de excepción se permite que algún proceso mejorada o descubierta en alguna sede de región sea difundida y aplicada en otras sedes, previa coordinación y aprobación de la sede regional y luego de la sede corporativa. La configuración taxonómica de red de esta corporación es: De acuerdo a la nacionalidad, la red es local, ya que los dueños pertenecen a un mismo país; De acuerdo al número, la red es polired, ya que hay más de 100 subsidiarias (países) en 5 regiones mundiales; De acuerdo a la propiedad, es totalmente perteneciente al sector privado; De acuerdo al desarrollo de procesos, desarrolla procesos integrados en las diversas áreas de negocios: Marketing, Finanzas, RRHH, Abastecimiento, etc.; De acuerdo al sentido abstracto-concreto, se privilegia una combinación de relaciones virtuales y presénciales; De acuerdo al ámbito de la relación, es preponderadamente interna.

\section{Condicionantes}

- Estrategia, la corporación tiene definida claramente sus postura estratégica en base a su visión y valores, destacando principios referidos a responsabilidad social, sustentabilidad del negocio, respeto por las relaciones con sus stakeholders, innovación, competencias organizacionales y del personal. En la actualidad también viene aplicando las tres posturas estratégicas; liderazgo en costos, mediante sus procesos de negocios mundiales estandarizados; diferenciación, tratando de agregar valor a una cartera de productos en cada una de sus líneas; y busca consolidar mercados mediante la regionalización con centros de negocios, para estar mas cerca de sus clientes.

- Ambiente, una interesante opción de administrar las actividades en mas de 100 países, ha sido la de agrupar los países por regiones a efectos de que en la medida de lo posible contextualizar aspectos sociales, políticos, económicos que podrían ser relativamente similares de manejar. Paralelamente a esta situación hay otra medida en relación la relación con clientes y proveedores los cuales podrían ser clasificados en a) de talla mundial y b) de talla regional/local.

- Tecnología, esta condicionante también es diferenciador de la corporación KAIZER, empleando tecnología de ultima generación en la producción de todas sus líneas de productos, también en tecnología informática en sus procesos de negocios administrativos 
integrados, mediante redes informáticas con apoyo de empresas del ramo de talla mundial, también debe resaltarse el know how de gestión a través del desarrollo de competencias de su personal (capital intelectual).

- Cultura, la postura organizacional de la corporación en relación a las relaciones

\section{Figura 4 - Red Corporación KAIZER}

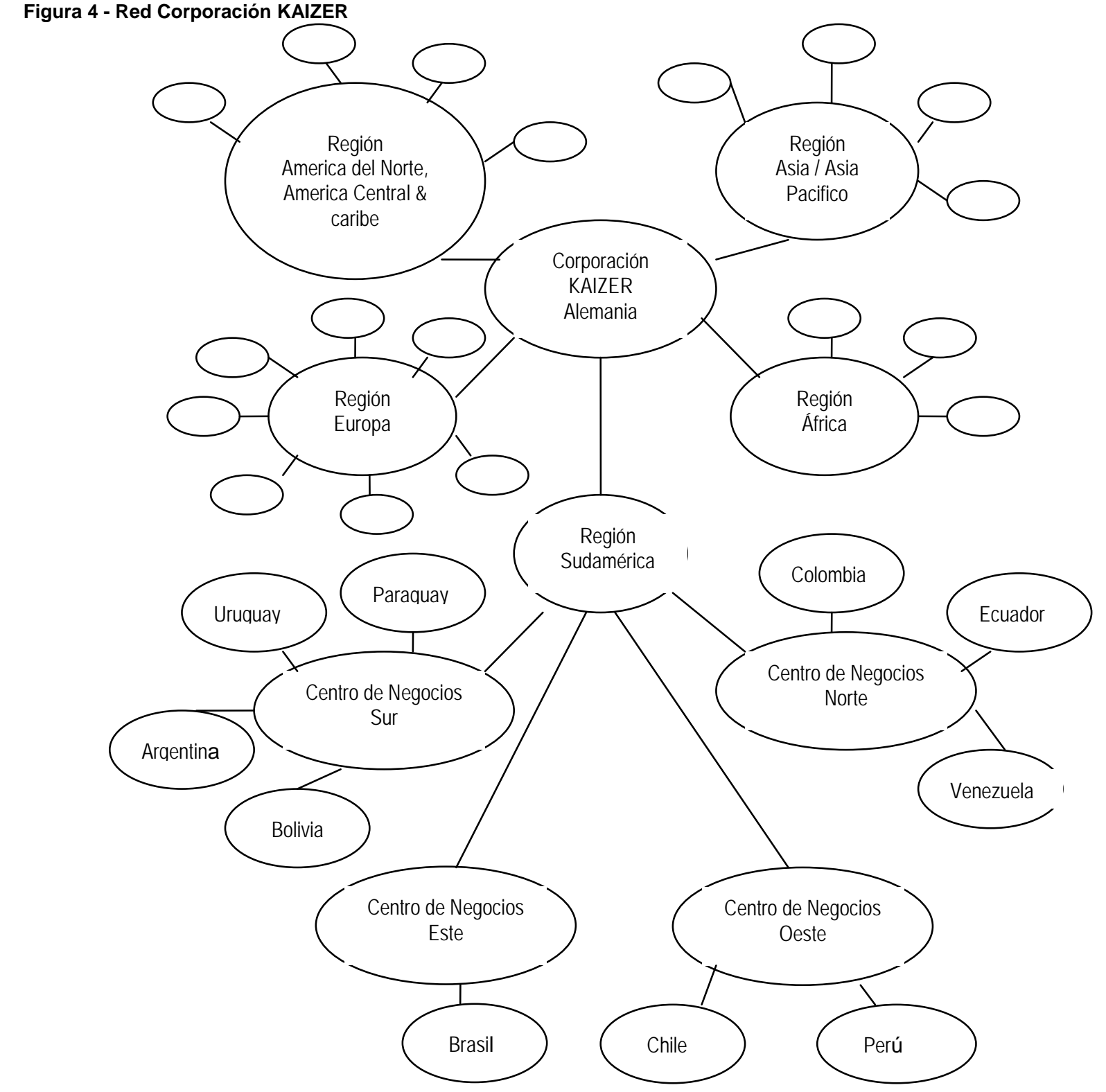

Fuente: Elaboración propia

humanas para aproximadamente 95,000 trabajadores en todo el mundo, es el del etnocentrismo, buscando consolidar una cultura uniformizada, guiada fuertemente por los principios de la sede matriz. 
Figura 5 - Estructura Orgánica de la Corporación KAIZER

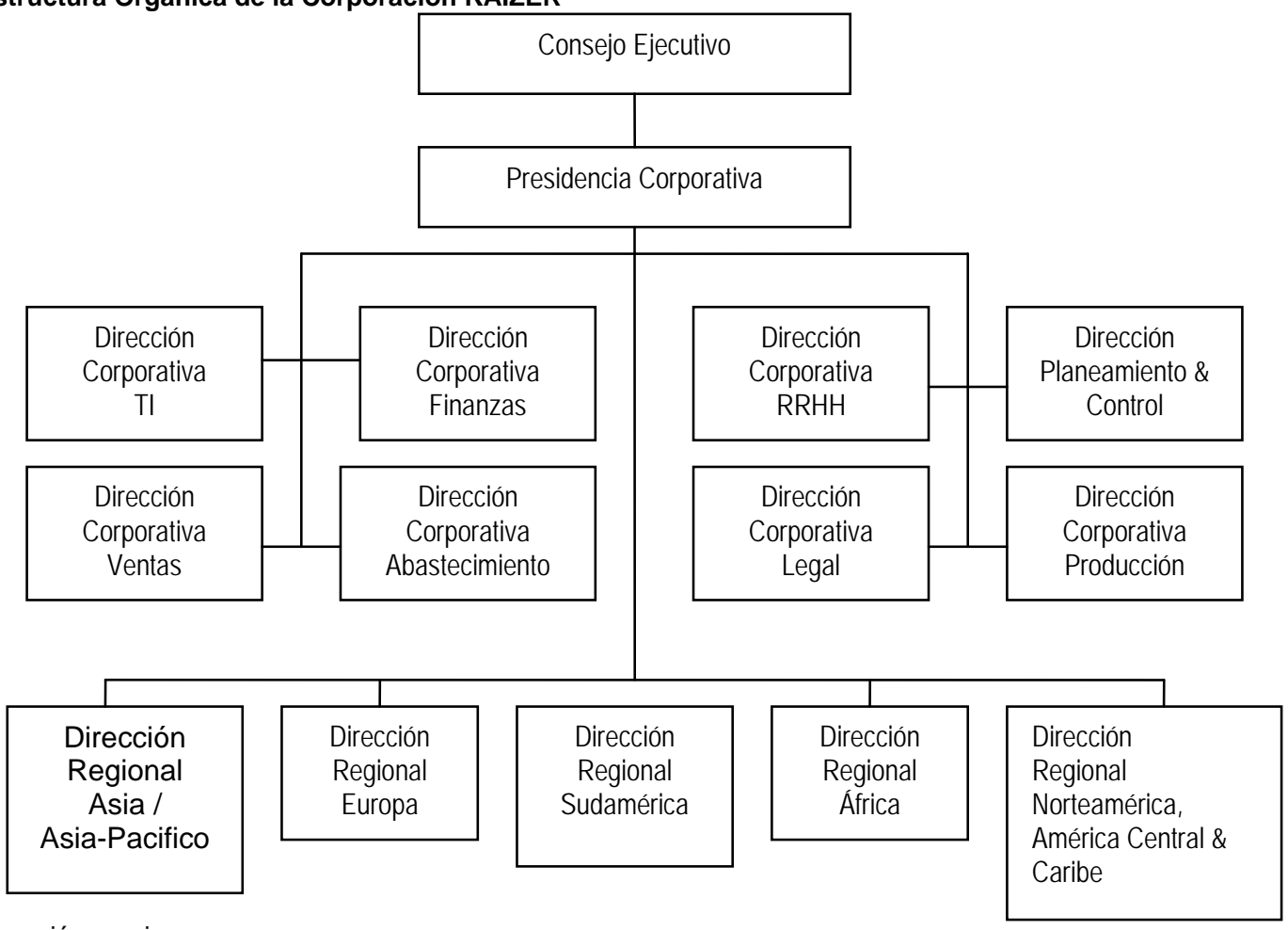

Fuente: Elaboración propia

Figura 6 - Estructura Orgánica Regional de la Corporación KAIZER

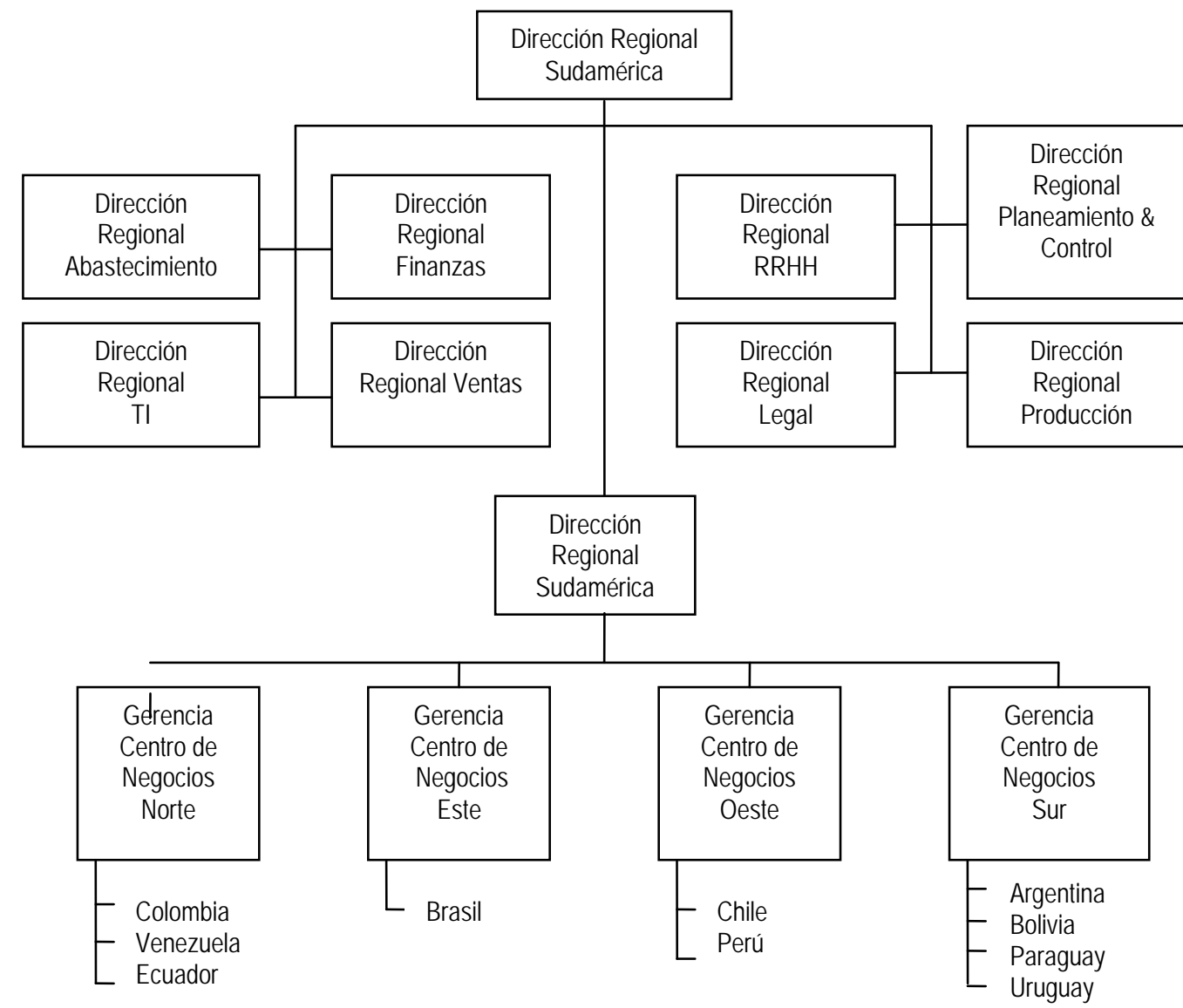

Fuente: Elaboración propia

Componentes 
- Departamentalización, los modelos organizacionales empleados es una combinación de red por las relaciones entre sede matriz, sedes regionales y sedes centro de negocios, lo que le da un criterio también geográfico y todavía con algunos rezagos de una estructura funcional con diversificación de productos.

- Línea/Asesoria, la relación de línea final corresponde a los centros de negocios, con actividades de producción y comercialización, pero que al mismo tiempo coordinan y/o son asesorados con sus áreas similares, pero de rango superior jerárquico (Ejemplo. Área de Finanzas de centro de negocios, con dirección regional de finanzas con dirección corporativa de finanzas).

- Descripción de actividades, el principio de este componente básicamente es la estandarización de procesos de negocios a nivel mundial, para lo cual sus sistemas integrados de gestión se encuentran uniformizados en todas sus sedes con base en redes.

- Cadena Jerárquica, la línea jerárquica corporativa queda bien definida por medio de los niveles siguientes: primer nivel; presidencia corporativa, direcciones corporativas, direcciones regionales, gerencias de centros de negocios, gerencia de países. Pero recordemos que también existen conexiones de coordinación/asesoria por áreas de expertise (Ejemplo: el gerente de regional de ventas depende del gerente general regional, pero tiene nexo de expertise con el director corporativo de ventas).

- Comunicación, éste componente se desarrolla mediante la combinación de redes virtuales y redes físicas presénciales, fomentada sobretodo por la relación de centros de negocios regionales donde hay permanente contacto de coordinación en los procesos de negocios.

\subsection{Caso 3: Corporación MEXCE}

Es una corporación Mexicana, fundada en 1935, actualmente con presencia en mas de 30 países distribuidos en los continentes americano, europeo y asiático, que tiene focalizado sus negocios en el sector cementero a nivel de producción y comercialización de productos tales como, cemento, concreto pre-mezclado y agregados varios del rubro. En la década de los años 80 se consolida como líder en el mercado mexicano y su expansión internacional comienza en los años 90.

La configuración general de la corporación se presenta a continuación: Una presidencia corporativa; como órganos de apoyo centrales: La vicepresidencia corporativa de administración y la vicepresidencia corporativa de Planeamiento financiero; como órgano de asesoria la vicepresidencia corporativa de desarrollo organizacional y como órganos de línea corporativa: la presidencia mundial de America del Norte, la presidencia mundial de Europa, la presidencia mundial de África, Asia y medio oriente y la presidencia mundial de America del Sur y del caribe (Figura 7)

La configuración en red se da por la integración y estandarización de procesos de negocios a través de los "células de procesos", que son equipos poli funcionales de alto desempeño constituidos por aproximadamente diez integrantes con expertises diferentes y que se encargan de definir los procesos centrales de la corporación. Existen las células de finanzas, de comercialización, de recursos humanos, de operaciones, de concreto, de control fiscal, de aprovisionamiento, de planeación, de tecnología informática. Los integrantes de cada célula son escogidos dentro de los mejores talentos de la corporación a nivel mundial y tienen como sede de trabajo diferentes países, dependiendo de quien jefatura la célula (owner o propietario). Cada célula administra diez procesos centrales y hasta 100 subprocesos, procurando integrarse sinérgicamente entre ellas. Este modelo esta dirigido por un Director general mundial de procesos ad hoc.

\section{Análisis del caso 3}

La internacionalización adoptada por la corporación MEXCE puede ser considerada como de tipo directa, puesto que desarrolla sus actividades con sedes propias en los países donde actúa. El modelo de internacionalización que adopta es eminentemente de tipo global, ya que las disposiciones emanadas de la matriz y de las células de procesos son de aplicación estándar en las subsidiarias. Eventualmente podrían considerarse aplicaciones locales de acuerdo a la necesidad requerida. 
Figura 7 - Estructura organizacional de la corporación MEXCE

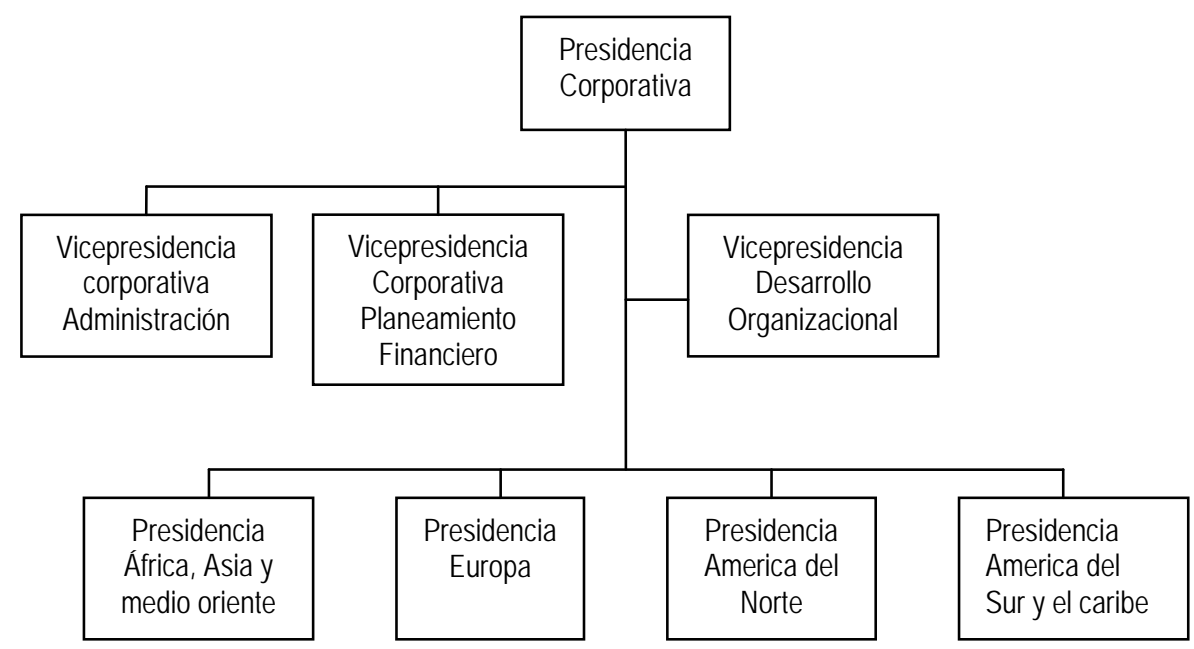

Fuente: elaboración propia

Figura 8 - Red de procesos corporación MEXCE

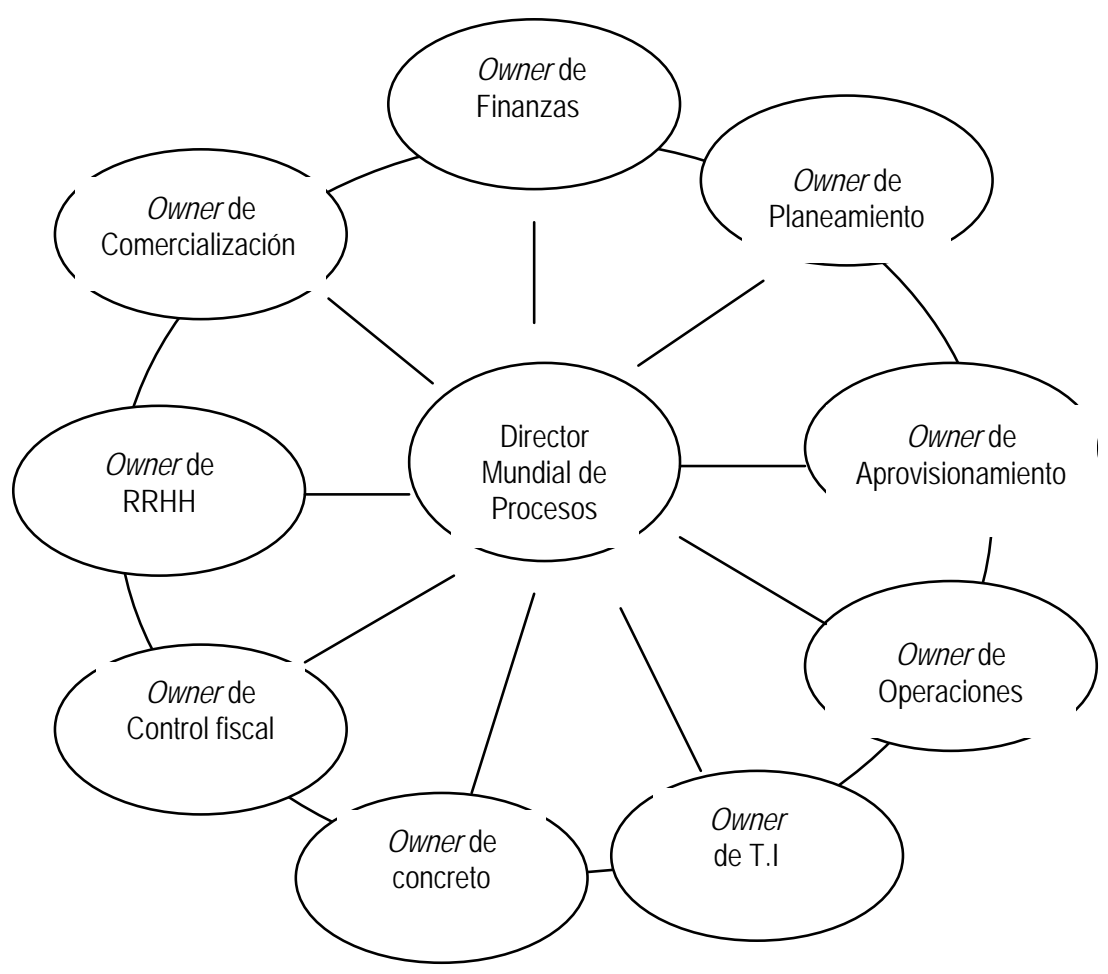

Fuente: Elaboración propia 
La configuración de la red puede ser tipificada como: De acuerdo a la nacionalidad, preponderantemente los dueños son mexicanos; De acuerdo al número, es una sola empresa; De acuerdo a la propiedad es de capital privado; De acuerdo al desarrollo de proceso, se plantea un sistema integrado de gestión incluyendo todas la expertises de gestión (marketing, finanzas, etc.); De acuerdo al sentido abstracto-concreto, hay una mezcla de empleos de medios virtuales y físicos; De acuerdo al ámbito de la relación es interna entre sus subsidiarias distribuidas por el mundo; De acuerdo al status de la relación, esta es formal y protocolada; De acuerdo al tiempo de duración, tiene una proyección sustentable en el tiempo, De acuerdo al sector de actuación, esta es focalizada en una actividad concreta; de acuerdo al porte de la empresa, es única, integrando a sus subsidiarias en el mundo.

\section{Condicionantes}

- Estrategia, la misión de MEXCE es satisfacer globalmente las necesidades de construcción de sus clientes y crear valor para sus accionistas, empleados y otros entes claves, considerándose como la organización cementera más rentable y fuerte del mundo. Su éxito se apoya en las siguientes fortalezas: administración experta, concentración en el negocio de cemento, concreto y agregado, bajos costos de operación, empleo de sistemas de vanguardia en tecnología informática y de producción, gestión financiera y estructura de capitales, experiencia en enfoques dinámicos. Las oportunidades que percibe se sitúan en inversiones a futuro, en tres zonas de acción y crecimiento bien definidas: América, el sistema Mediterráneo y el Sur-Este asiático y a largo plazo China. En contraposición la amenaza principal que perciben se refiere a los movimientos estratégicos de los "jugadores globales" de la industria, los cuales están compitiendo por dos tipos de mercados: el mercado de producto/servicios y el mercado financiero. De forma general se puede afirmar que MEXCE es una empresa cuya postura estratégica es de continuo crecimiento y desarrollo, mirando al futuro de forma global.

- Ambiente, el consejo de administración del grupo MEXCE tiene postura emprendedora sobre el liderazgo de su presidente, el cual simultáneamente ejerce las funciones de CEO de la empresa. El se caracteriza por adoptar decisiones visionarias en las búsqueda del mejoramiento ante los contextos cambiantes de los negocios, siendo considerado un prestigiado y reconocido ejecutivo, no solo de la industria cementera, sino también en otros sectores donde ocupa cargos de consejero de administración en otros grupos empresariales de renombre. En relación a los mercados de clientes, para MEXCE existen dos segmentos definidos: el primero relacionado en los países en vía de desarrollo, el cual se caracteriza por la compra minorista destinado al consumidor final, el segundo mercado se dirige en un $80 \%$ de las ventas a grupos industriales constructores, La relación con los proveedores también se produce primordialmente por medios electrónicos permitiendo la fidelización con procesos comerciales interorganizacionales.

- Tecnología, MEXCE emplea la tecnología informática a efectos de poder optimizar sus operaciones, ofrecer servicios de valor agregado a sus clientes y generar valor para sus grupos de interés. Sus competencias informáticas se manifiestan en la plataforma propia que le permite estandarizar a nivel mundial sus operaciones de proceso de negocios. En las palabras de su CEO “ Aprovechemos el poder de la tecnología e Internet para mejorar y simplificar nuestras operaciones globales, compartir nuestras mejores practicas, centrarnos en las actividades medulares del negocio $y$ lógicamente quedar mas cerca de nuestros clientes

- Cultura, la corporación MEXCE cuenta a nivel mundial con aproximadamente 24,000 funcionarios, los cuales tienen como una de sus características principales, la disposición y capacidad para adaptarse a situaciones y sedes donde se precisa de ellos. Operar en un entorno así demanda un lenguaje común, una forma estandarizada de realizar las cosas, lo cual le permita trabajar mas eficientemente y de forma adecuada con sus colegas de todo el mundo. En ese sentido la corporación adopta una postura típicamente etnocéntrica, que se fundamenta en el paternalismo centralizado de la matriz en sus respectivas subsidiarias.

\section{Componentes}

Departamentalizacion, visualmente configuración tendría las características de algún organigrama tradicional, mas al analizar la dinámica de funcionamiento, es ahí que se puede notar claramente que es una estructura por procesos. Una muestra concreta de esta propuesta son las nueve celulas de procesos 
encargadas de administrar todos los procesos y sub-procesos que contempla la corporación, aplicando sistemas integrados de gestión por procesos. Estos procesos permiten una estandarización a nivel corporativo mundial en procesos de comercialización, contraloría fiscal, concreto, operaciones, finanzas, $\mathrm{RH}$, contraloría operativa, planeamiento, abastecimiento.

- Línea/Asesoria, en la corporación MEXCE estas actividades se sobreponen estratégicamente y coordinadamente. Por un lado existe un staff central corporativo de comando y al mismo tiempo asesora a las diversas sedes mundiales vía gestión de los procesos estandarizados de negocios. Ya la actuación de las sedes mundiales de regiones/países, se caracterizan principalmente por actuar operacionalmente en la línea de frente del negocio, es decir, "producir y vender", y solicitan apoyo en caso fuese necesario al staff corporativo central en las diversas competencias especificas. Una entidad típicamente de staff y que coordina la gestión de los procesos son las células, las cuales establecen y desarrollan las mejores prácticas dentro del grupo MEXCE.

- Descripción de actividades, de forma general son estandarizadas, a través de procesos de negocios que representan sus mejores practicas de gestión integrada teniendo como soporte plataformas tecnológicas sobretodo aguardando obtener resultados métricoscuantitativos que muestren la eficiencia de su aplicación. Esta descripción estandarizada representa para la corporación MEXCE, la capacidad de uniformizar criterios mundiales, rapidez en las decisiones, integración de actividades y flexibilidad en los movimientos del personal en las diversas sedes mundiales, con lo cual "se evita le hecho que la idiosincrasia-país de cada funcionario pudiese afectar la idiosincrasia MEXCE mundial.

- Cadena jerárquica, la corporación tiene una característica platicurtica (horizontalizada) con una media de cuatro niveles centrales corporativos y a nivel sede región/país. El sentido de comando tiene perfil de procesos cruzados y funciones cruzadas (cross-process y cross-funtions). El cual queda demostrado en los siguientes hechos:

Un vicepresidente de país se une jerárquicamente al Presidente del respectivo País; también al vicepresidente corporativo central del área 0 proceso de competencia. Ej. El Vice-presidente de planeamiento de España, se reporta al presidente de MEXCE España y al vicepresidente corporativo de planeamiento estratégico de la matriz;

Un vicepresidente de línea de País España se une jerárquicamente al Presidente de MEXCE España;

Los Presidentes de Países se unen directamente al Presidente de zona geográfica mundial respectivo. Ejemplo: el Presidente de MEXCEVenezuela se une directamente con el Presidente MEXCE de América del Sur \& caribe;

Los Presidentes de zonas mundiales se unen directamente al CEO;

Los Vice-Presidentes corporativos se unen directamente al CEO.

Las celulas de gestión de los procesos dependen del Director mundial de procesos. Internamente cada celula tiene su estructura jerárquica comandada por el Owner que generalmente también es un Presidente de zona o País.

- Centralización/descentralización, la corporación MEXCE dentro de sus premisas de funcionamiento establece tres tipos de actividades delimitadas a nivel corporativo: a) Funciones Integradas, son aquellas que implican tolerancia cero para ser modificadas. Son establecidas a nivel corporativo y entre ellas tenemos Informática, Tesorería, Aprovisionamiento, fiscal; b) Funciones Coordinadas, son aquellas donde se negocian una coordinación entre el nivel corporativo central y el nivel zona/país mundial en los campos de $\mathrm{RH}$, planeamiento, tecnología; c) Funciones Locales, son aquellas que se permiten delegar hasta un pequeño porcentaje a cada sede mundial (zona/país) debido a que son procesos operativos de línea de frente que precisan adaptarse a cada realidad local. Abarcan los aspectos comerciales, logísticos, operacionales y ready-mix.

- Comunicación, si existe un aspecto de competencias reconocidas en la corporación MEXCE esa es su capacidad tecnológica informática y de comunicación satelital, constituida por plataformas virtuales rápidas y consistentes a nivel mundial, en todo el proceso o función que hace fluida, rápida, integrada y directa la comunicación corporativa. Todo esta sincronizado en la red, no solo internamente sino también con proveedores y clientes. Es preciso también resaltar que no obstante las operaciones primordialmente sean electrónicas, no se deja de lado las comunicaciones y relaciones 
interpersonales entre los trabajadores, el cual también es considerado fundamental para la cultura organizacional.

\section{Consideraciones finales}

El diseño de red organizacional es una configuración de "ultima generación" que aun se encuentra "under construction", lo que implica seguramente todavía una falta de estandarización de sus conceptos, fundamentos, taxonomias y características, las cuales recién vienen conociéndose y asimilándose gradualmente tanto por parte del sector académico como empresarial. Más que una moda, ésta forma de organización se viene dando por la necesidad de tener que responder a los nuevos desafíos de gestión no solo local sino de internacionalización.

En este documento apreciamos, tres casos ilustrativos de corporaciones con actividades internacionales en nuestra región sudamericana, como efectivamente en un contexto de internacionalización de negocios, el diseño de red se convierte en una opción factible, practica y real de afrontar esos desafíos, lo que no significa dejar de observar el alto grado de complejidad que eso implica, comenzando por tener que replantear viejos paradigmas organizacionales.

En el primer caso se presenta una corporación peruana, líder nacional en sus actividades empresariales, oriunda de la región sudamericana, la cual nos muestra como una corporación puede configurar su red internacional en la región latinoamericana, a partir de una sinergia de empresas especializadas del mismo país (y del mismo grupo), para dar apoyo a sus procesos de negocios centrales integrados y centralizándose en su core-competences relacionado a comercialización de líneas de productos de belleza (las actividades de producción son tercerizadas), tomando como referencia la similaridad de gustos de los latinoamericana. En el segundo caso, se presenta una corporación alemana de primer orden, con actividades mundiales y lógicamente en nuestra región latinoamericana., la cual emplea una red mundial geográfica por regiones y dentro de las cuales se establecen centros de negocios, para desarrollar un mejor empleo de los recursos asignados y con la idea de fidelización y complemento a sus relaciones mundiales de negocios con otras empresas también de talla mundial y una segunda apertura a empresas regionales en actividades esenciales de producción y comercialización en sus diversos segmentos divisionales de productos. En el tercer caso apreciamos la experiencia de una corporación red mexicana que actuando focalizadamente en un sector ha sabido desarrollarse y posicionarse internacionalmente en base a sus modelo de células de proceso con integrantes polivalentes y sediadas en diversos lugares del mundo, peor a la vez integrando y estandarizando procesos a nivel de toda la corporación.

Independientemente de las particularidades propias de cada corporación, a modo de análisis ha podido notarse en el análisis de condicionantes y componentes, algunas características nuevas, originales y sobretodo convergentes en los preceptos teóricos de la estructura organizacional en red.

En cuanto a la estrategia queda clara la postura por la internacionalización directa basada en el modelo global como hilo conductor de integración centralizada desde la matriz en relación a la subsidiaria. En relación al ambiente se observa la fuerte y estrecha relación de las corporaciones con sus stakeholders no solo en el país de origen sino en el de las subsidiarias. Queda claro también que el empleo de medios informáticos-virtuales y electrónicos es un soporte fundamental para la aplicación del modelo de red. También se ha observado la fuerte postura etnocéntrica, tratando de inculcar los valores de la sede origen en cada una las subsidiarías.

La departamentalización se ha caracterizado por la aplicación de procesos integrados de negocios, característica clave en un modelo de red, en relación a las funciones de los modelos clásicos tradicionales. Las relaciones de unidades orgánicas de línea con las de staff comienzan a integrarse simultáneamente constituidas de funcionario poli funcionales. La descripción de actividades se sustentan en el criterio de "estandarización de procesos" formales y protocolados de aplicación universal dentro de la corporación. Las cadenas jerárquicas presentan una tendencia a la disminución de niveles formales, buscando más que todo una horizontalizacion y sobretodo la jerarquía de las competencias y meritocracias más que las jerarquías oficiales. En cuanto a los niveles de centralización/descentralización, puede observarse que las cuestiones estratégicas aun se conservan en las sedes matrices, pero la ejecución operativa es de aplicación de las subsidiarias de líneas del frente. Finalmente la comunicación se convierte en el eje o enlace intrínseco del funcionamiento de las redes haciendo uso de medios virtuales de ultima generación, pero sin descuidar la comunicación face to face 
Lo anotado precedentemente representa una señal clara de que tanto la teoría como la práctica están caminando juntas con proyecciones de consolidación a mediano y largo plazo, dando sustentabilidad al modelo de redes organizacionales como una opción a ser tomada en cuenta en los diseños corporativos modernos.

\section{Referencias}

BATEMAN, T.; SNELL, S. Administração: construindo vantagem competitiva. São Paulo: Atlas, 1998.

BARDIN, P. Análise de conteúdo. Lisboa: Edições 70, 1977.

\section{BARTLETT, A.; GHOSHAL, S. Gerenciando empresas no exterior: a solução transnacional. São Paulo: Makron Books, 1992.}

BEDEIAN, A.; ZAMMUTO, R. Organizations: theory and design. Chicago: The Dryden Press, 1991.

CRESWELL, J. W. Research design: qualitative \& quantitative approaches. Thousand Oaks: Sage, 1994.

GALBRAITH, J. Organization design. Reading: Addison-Wesley, 1977.

GROSSE, R.; KUJAWA, D. International business: theory and managerial applications. 2. ed. Chicago: Irwin, 1992.

GIBSON, J.; IVACENEVICH, J.; DONNELY, J. Organizações: comportamento, estrutura, processos. São Paulo: Atlas, 1988.

GIL, A. Como elaborar projetos de pesquisa. São Paulo: Atlas, 1988.

GHOSHAL, S.; BARTLETT, C. A organização individualizada. Rio de Janeiro: Campus, 2000.

HALL, R. Organizações: estrutura e processos. 3. ed. Rio de Janeiro: Prentice Hall, 1984.

IANNI, O. Teorias da globalização. 4 ed. Rio de Janeiro, Civilização Brasileira, 1997.

JONES, G. Organizational theory: text and cases. Reading: Addison-Wesley, 1995.

LOUFFAT, E. Estructura organizacional en red y sus negociaciones en contexto de alianzas estratégicas. Lima: ESAN, 2003.

MONTANA, P. J.; CHARNOV, B. Administração. São Paulo: Saraiva, 2003. 